\title{
Clinicoetiological Analysis of Neonatal Hyperbilirubinemia in a Tertiary Care Hospital
}

\author{
Tanvi Prabhu ${ }^{1}$, Dr. Esha Mati ${ }^{2}$, Dr. Mamata Hegde ${ }^{3}$ \\ ${ }^{1,2,3}$ Shrimati Kashibai Navale Medical College and GH. Narhe, Pune, Maharashtra, India
}

\begin{abstract}
Jaundice is the most common cause of neonatal admission in hospitals. If uncontrolled, severe hyperbilirubinemia can cause permanent neurological impairment called kernicterus. The aim of this study was to analyse the pattern, severity, causes, risk factors, treatment and outcome of neonatal hyperbilirubinemia in our hospital thereby helping identify common preventable risk factors. Methodology: This was a prospective study conducted on jaundiced neonates with serum bilirubin > 5mg/dl admitted in PNC and NICU wards over a period of three months. Maternal, antenatal history was taken. Laboratory parameters included serum bilirubin, Hb, blood counts, Blood groups. Treatment modality and outcome was noted during the hospital stay. Results: Of the 102 cases, $23 \%$ were preterm babies, and $38 \%$ had low birth weight. The commonest cause of neonatal hyperbilirubinemia was physiological jaundice (42\%) Pathological jaundice cases had significantly higher bilirubin (17.62 \pm 6.11$)$ than physiological jaundice cases $(12.5 \pm 3.08)$ with $p$ value $<0.001$.Phototherapy was the commonest mode of treatment with good results.
\end{abstract}

Keywords: bilirubin, etiology, hyperbilirubenemia, neonates

\section{Introduction}

Neonatal hyperbilirubinemia is one of the commonest causes of admission of neonates in hospitals. Almost $60 \%$ of term babies suffer from jaundice in the first week of their life. Neonatal hyperbilirubinemia is defined as total serum bilirubin level above $5 \mathrm{mg} / \mathrm{dl} .{ }^{1}$ The overall incidence of neonatal jaundice reported by many studies done across India ranges from $54.6 \%$ to $77 \%{ }^{2}$

If left uncontrolled, severe hyperbilirubinemia may later cause permanent neurological impairment called kernicterus. Although a safe threshold for total serum bilirubin has not been defined, most physicians have adopted a bilirubin level more than $20 \mathrm{mg} / \mathrm{dl}$ as indicator of vulnerability to neurotoxicity. ${ }^{3}$

Neonatal jaundice is associated with a wide variety of known physiological and pathological conditions with varying outcomes. The wide variety of risk factors that have been associated with hyperbilirubinemia in newborns include prematurity, previous sibling with jaundice, $\mathrm{ABO}$ incompatibility, inadequate breast feeding, infections, birth trauma etc. ${ }^{4}$

Etiological factors leading to hyperbilirubinemia vary among different geographic regions. ${ }^{3}$ Even the bilirubin concentrations considered harmful or neurotoxic may vary with geographical conditions and ethnic groups. ${ }^{1}$ The studies done in parts of northern India have reported sepsis as the leading pathological cause of significant hyperbilirubinemia $(>15 \mathrm{mg} / \mathrm{dl}){ }^{2}$ Regions of Maharashtra in western India showed blood group incompatibility to be the major cause of pathological jaundice. ${ }^{5}$ However in a study done in Taiwan the common cause of neonatal jaundice was exclusive breast feeding and G6PD deficiency. They even reported Chinese herb intake and Downs syndrome as etiologic factors. ${ }^{3}$

With this background, the aim of this study was to analyse the pattern, causes, risk factors, treatment and outcome of neonatal hyperbilirubinemia in our hospital.

\section{Materials and Methods}

This was a prospective study conducted on jaundiced neonates at PNC and NICU wards of SKNMC and GH over a period of three months (April - June 2015).Total of 102 neonates were studied.

Inclusion Criteria- Jaundiced neonates admitted in PNC and NICU wards identified clinically using Kramers criteria, and their blood samples were sent for bilirubin estimations to confirm hyperbilirubinemia. Neonates were included in study if their bilirubin levels exceeded $5 \mathrm{mg} / \mathrm{dl}$. Parent's consent was taken.

Exclusion Criteria- Jaundiced neonates that came only on OPD basis, or din't get admitted in the wards, or got discharged against medical advice, whose parents refused to consent.

Each baby delivered at hospital was carefully observed from birth onwards in day light, for appearance of jaundice. Cases were evaluated along with the maternal and antenatal history. Laboratory parameters included serum bilirubin (total, direct, indirect), $\mathrm{Hb}, \mathrm{TLC}, \mathrm{DC}, \mathrm{Cell}$ morphology. Bilirubin estimation was done using Diazo method. Blood groups of mother and baby were assessed. Weight of babies and their feeding patterns was assessed and monitored. Thorough clinical examination of babies was done. Follow up of neonates was done until discharge. Treatment included phototherapy and exchange transfusion depending on the severity and cause of the jaundice. Treatment modality and outcome was noted during the hospital stay.

\section{Results}

A total of 102 cases were studied. Male babies were affected more often $(54 \%)$ than female $(46 \%)$. The mean age of neonates was $3.93 \pm 2.5$ days. The mean age of mothers was $24.1 \pm 4$ years; with the youngest being 19 and the oldest 37 years. The mean gestation age was calculated to be $37.24 \pm 2$ 


\section{International Journal of Science and Research (IJSR) \\ ISSN (Online): 2319-7064 \\ Index Copernicus Value (2013): 6.14 | Impact Factor (2015): 6.391}

weeks. $58 \%$ were born via normal labour, $42 \%$ by caesarean section. Almost 23\% were preterm.

Table 1: Distribution according to gestational age at birth

\begin{tabular}{|c|c|c|}
\hline & Number & Percentage \\
\hline $\begin{array}{c}\text { Preterm } \\
\text { babies }\end{array}$ & 23 & $22.5 \%$ \\
\hline $\begin{array}{c}\text { Term } \\
\text { babies }\end{array}$ & 75 & $73.5 \%$ \\
\hline Post term & 4 & $4 \%$ \\
\hline
\end{tabular}

Table 2 shows distribution of jaundiced babies depending on birth weight

Table 2: Distribution of babies based on birth weight

\begin{tabular}{|c|c|c|}
\hline Birth weight & Number & Percentage \\
\hline Normal & 61 & $60 \%$ \\
\hline $\begin{array}{c}\text { LBW } \\
(1500-2500 \mathrm{mg})\end{array}$ & 39 & $38 \%$ \\
\hline $\begin{array}{c}\text { VLBW } \\
(1000-1500 \mathrm{mg})\end{array}$ & 2 & $2 \%$ \\
\hline
\end{tabular}

Majority of the cases had their total bilirubin levels below $15 \mathrm{mg} / \mathrm{dl}$ mainly comprising the physiological jaundice cases as shown in fig (1).

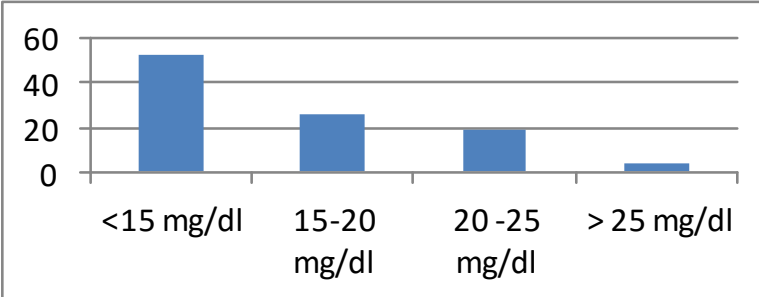

Figure 1: Number of neonates with different bilirubin levels

As is evident in figure (2) and table (3), physiological jaundice was commonest in babies and the most common cause of patholgical hyperbilirubinemia was ABO Incompatibility (27\%) followed by $\mathrm{Rh}$ incompatibility (12 $\%)$.

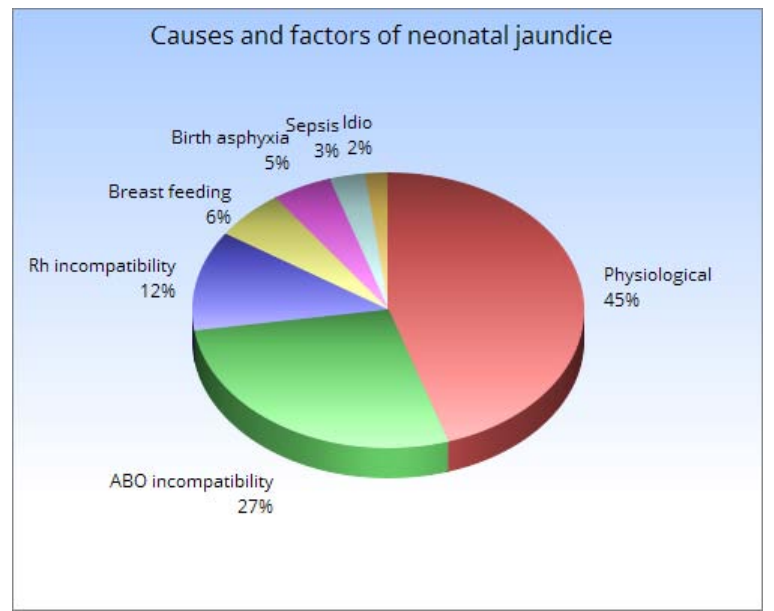

Figure 2: Causes and aggravating factors of neonatal jaundice
Table 3. Causes and aggravating factors of hyperbilirubinemia

\begin{tabular}{|c|c|c|}
\hline $\begin{array}{c}\text { Cause or aggravating } \\
\text { factor }\end{array}$ & $\begin{array}{c}\text { Number of } \\
\text { cases }\end{array}$ & Percentage \\
\hline Physiological & 46 & $45.09 \%$ \\
\hline ABO incompatibility & 28 & $27.45 \%$ \\
\hline Rh incompatibility & 12 & $11.76 \%$ \\
\hline Breast feeding & 6 & $5.88 \%$ \\
\hline Birth asphyxia & 5 & $4.9 \%$ \\
\hline Sepsis & 3 & $2.94 \%$ \\
\hline Idiopathic & 2 & $1.96 \%$ \\
\hline
\end{tabular}

Mean bilirubin values for pathological cases (17.62 \pm 6.11 $\mathrm{mg} / \mathrm{dl}$ ) was significantly higher than physiological jaundice ( $12.53 \pm 3.08 \mathrm{mg} / \mathrm{dl}$ ) with a 'p' value $<0.001$.

Bilirubin levels were higher in case of ABO incompatibility $(19.4 \pm 2.1 \mathrm{mg} / \mathrm{dl})$ than $\mathrm{Rh}$ incompatibility $(11 \pm 0.9 \mathrm{mg} / \mathrm{dl})$. Among the jaundiced babies, 22 had bilirubin levels above $20 \mathrm{mg} / \mathrm{dl}$ of which majority were due to ABO incompatibility (9).Six cases were attributed to breast feeding jaundice. Low $\mathrm{Hb}$ levels $(<10 \mathrm{mg} / \mathrm{dl})$ were observed in five cases of which four had Rh incompatibility.

The mean age of presentation with jaundice was three days. $\mathrm{ABO}$ and $\mathrm{Rh}$ incompatibility cases presented earlier on (within 3- 4 days) with jaundice than breast feeding jaundice cases (6-7 days).

Table 4: Treatment modality used

\begin{tabular}{|l|c|c|}
\hline & $\mathrm{n}=102$ & $\begin{array}{c}\text { PERCENTAGE } \\
\%\end{array}$ \\
\hline PHOTOTHERAPY & 93 & 91.17 \\
\hline EXCHANGE TRANSFUSION & 2 & 1.96 \\
\hline NO TREATMENT REQUIRED & 7 & 6.86 \\
\hline
\end{tabular}

All the babies showed significant improvement with phototherapy and exchange transfusion. Some physiologically jaundiced babies improved without any active treatment and were advised daily sun exposure until improvement. Exchange transfusion was given only in severe cases of jaundice due to $\mathrm{ABO}$ incompatibility.

\section{Discussion}

Our study is the first of its kind in our hospital setup. Many studies in the past show a male preponderance in neonatal jaundice cases similar to our study. 2, 6,7 Prematurity is a prominent risk factor for neonatal hyperbilirubinemia. Studies done by Choudhary et al and Shah et al, found $37 \%$ and $30 \%$ cases respectively to be preterm babies like our study $(23 \%))^{7,}{ }^{8}$ Preterm babies are at risk of developing jaundice due to the immature liver. Generally babies with bilirubin levels above $20 \mathrm{mg} / \mathrm{dl}$ are considered to be at higher risk of developing kernicterus, however several studies have shown kernicterus to appear at much lower levels of $10-18$ $\mathrm{mg} / \mathrm{dl}$ in premature infants. ${ }^{9}$

Birth weight also plays a significant role, as observed in our study where $38 \%$ of the jaundiced babies had low birth 


\section{International Journal of Science and Research (IJSR) \\ ISSN (Online): 2319-7064}

Index Copernicus Value (2013): 6.14 | Impact Factor (2015): 6.391

weight, in accordance with findings by Narang (34.5\%), $\operatorname{Shah}(27 \%)$ and Choudhary et $\operatorname{al}(42 \%)$. 9, 8, 10

Several studies have reported physiological jaundice to be the most common cause of neonatal jaundice like our study. ${ }^{2}$ ${ }^{6,7}$ In the fetal stage bilirubin is excreted by the placenta, and after birth in the neonatal stage, the bilirubin has to be be excreted from hepatic cells into the biliary system, so the transition from the fetal stage to the neonatal stage becomes crucial reason for physiological jaundice

Similar to our findings, Rama et al, Shah et al, Joshi et al, reported $\mathrm{ABO}$ incompatibility as the most common cause of pathological jaundice. ${ }^{6,} 8,{ }^{11}$ Sepsis was found to be commonest cause of pathological jaundice in studies by Bahl et al $(10.5 \%)$ and choudhary et al $(17.6 \%)$ in Shimla and Bangladesh respectively. ${ }^{2,} 7$ Another study in Chandigarh found G6PD deficiency (17\%) to be the leading cause of pathological jaundice followed by sepsis $(9 \%) .{ }^{10}$

In our study blood incompatibility was the most common cause of pathological jaundice. Like our findings Hao weng et al found $\mathrm{Rh}$ incompatibility to be less common but causing more severe hyperbilirubinemia and haemolytic jaundice than ABO incompatibility. ${ }^{12}$ Choudhary et al found $\mathrm{ABO}$ incompatibility $(11.5 \%)$ to cause almost twice the number of pathological jaundice as $\mathrm{Rh}$ incompatibility (5.4\%) much like our findings. ${ }^{7}$

Birth asphyxia is a serious aggravating factor in jaundice cases.7.5\% and $10.8 \%$ babies had birth asphyxia in studies done by Kulkarni et al and Rama et al. ${ }^{5,6}$ In our hospital too, $4.9 \%$ babies had asphyxia that worsened the jaundice in the infants.

Few have reported sepsis as the more common cause of pathological jaundice. ${ }^{2,7}$ In our study three babies had sepsis comprising $2.94 \%$ of cases. Our findings are in concordance with findings of Narang et al and Singhal et al. ${ }^{10,13}$ A study in Maharashtra reported $8.3 \%$ of cases with sepsis. ${ }^{5}$ Sepsis leads to RBC hemolysis in circulation and even hepatic infection, thereby causing hyperbilirubinemia. With better facilities available in urban tertiary care hospitals and aseptic precautions taken during delivery, the sepsis cases should decline in future.

Majority of the babies were on exclusive breast feeding $(91 \%)$. Almost $6 \%$ developed breast feeding jaundice due to inadequate milk production or infrequent feeds. Shao wen at al reported breastfeeding as the commonest etiological factor for jaundice. ${ }^{3}$ This may be attributed to the late or insufficient milk production by the mother or because of poor feeding techniques. Reduced feeding leads to dehydration causing lesser bowel movements in the newborn, which results in decreased bilirubin excretion from the body. ${ }^{14}$

Often multiple etiological factors occur together, and these combined etiologies may result in greater severity of neonatal hyperbilirubinemia thereby putting the baby at higher risk of developing neurological complications. ${ }^{3}$
The cause of two cases could not be identified. Various studies from across our country have shown Idiopathic neonatal jaundice cases to range from $8.8-57 \%{ }^{10}$

A high neonatal readmission rate, within days of discharge from hospital has been noted in Canada, mainly due to severe hyperbilirubinemia. ${ }^{15}$ Infants jaundiced in the first few days are more likely to develop hyperbilirubinemia later. ${ }^{9}$ Early detection and management of neonatal jaundice is thus very important. The anxiety caused by such hospital admissions can be prevented if the risk factors can be identified before discharge. ${ }^{15}$ Before neonates are discharged those at risk of developing high bilirubin levels need to be identified. The risk assessment is better when the clinical risk factors are assessed along with serum bilirubin levels. ${ }^{16}$

All the babies showed good results after phototherapy. A majority of jaundiced neonates recover with phototherapy, very few who don't, need to undergo exchange transfusion that removes partially hemolysed and antibody coated blood cells. ${ }^{1}$ Recently even Intravenous immunoglobins have been used as additional treatment modality in cases of blood group incompatibility to reduce the bilirubin levels. ${ }^{12}$ With such efficient treatment modalities available, all that is needed is to identify such babies at risk.

\section{Conclusion}

Physiological Jaundice was found to be the commonest cause of jaundice. $\mathrm{ABO}$ and $\mathrm{Rh}$ incompatibility were mainly responsible for pathological jaundice.

Phototherapy was found to be a safe, cheap and effective way to reduce bilirubin levels in neonatal jaundice.

\section{References}

[1] Meredith Porter, Beth Dennis. Hyperbilirubinemia in healthy term newborn. Am Fam Physician 2002; 65:599606.

[2] Lalita bahl, rakesh Sharma, jaishree Sharma, Etiology of neonatal jaundice in shimla. Indian paediatrics.1994; 31:1275-1278.

[3] shao wen cheng, ya wen chiu, yi hao weng. Etiological analyses of marked neonatal hyperbilirubinemia in a single institution in taiwan.Chang Gung Med J 2012; $35: 148-54$

[4] Alastair Jj, Wood Md. neonatal hyperbilirubinemia. N Engl J Med.2001; 344(8):581-589.

[5] Kulkarni S.K., Dolas A.L, Doibale M.K. risk factors of neonates with indirect hyperbilirubinemia in a tertiary care hospital. International Journal of Basic and Applied Medical Sciences 2014 Vol. 4 (1).395-399

[6] Rama Devi, M. Bhuvaneswari, G. S. Ram Prasad, Sireesha. Clinical Profile and Outcome of Term and Preterm Newborns with Hyperbilirubinemia Admitted In SNCU of A Teaching Hospital. Journal of Evidence based Medicine and Healthcare; 2015; 2 (14): 2089 2095

[7] Choudhary habibur, abul hasan, farhana yasmin.Outcome of neonatal hyperbilirubinemia in a 
tertiary care hospital in Bangladesh.malaysian journal med sci 2010;17 (2):40-44.

[8] Amar shah, ck shah, venu shah. Study of haematological parameters among neonates admitted with neonatal jaundice.journal of evolution of medical and dental sciences.2012;1(3):203-208.

[9] Maisels JM, Newman TB. Predicting hyperbilirubinemia in newborn: the importance of timing. Commentary. Pediatrics 1999; 103: 493-494.

[10] Anil narang, geeta gathwala, Praveen kumar.neonatal jaundice: an analysis of 551 cases. Indian paediatrics.1997; 34 :429-432.

[11] Joshi bd, singh r, mahato d, Prasad r. A clinic laboratory profile of neonatal hyperbilirubinemia in term babies at B.P Koirala institute of health sciences, dharan, Nepal.journal of Nepal health research council.2004; 2(2): 28-30.

[12] Yi hao weng, ya wen chiu.Spectrum and outcome analysis of marked neonatal hyperbilirubinemia with blood group incompatibility.Chang Gung Med J 2009; 32:400-408.

[13] Singhal PK, Meherban Singh, Paul VK, Deorari AK and Ghorpade MG. Spectrum of neonatal hyperbilirubinemia. An analysis of 454 cases. Indian Paediatrics 1992; 29:319-325.

[14] Shailender Mehta, Praveen Kumar, Anil Narang. A Randomized Controlled Trial of Fluid Supplementation in Term Neonates With Severe Hyperbilirubinemia The Journal of pediatrics, 2005 - Elsevier

[15] Michael sgro, douglas Campbell, vibhuti shah. Incidence and causes of severe neonatal hyperbilirubinemia in Canada.CMAJ.2006;175(6):587-590

[16] Umesh pathak, Deepak chawla, Saranjit Kaur, Sukhsham jain. Bilirubin normogram for prediction of significant hyperbilirubinemia in north Indian neonates. Indian paediatrics $2013 ; 50: 383-389$ 